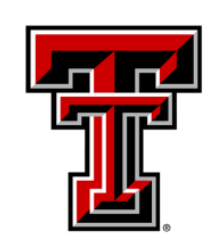

TEXAS TECH UNIVERSITY

Libraries"

\title{
ReACHing OUt: Connecting Students to Their Personal LIBRARIAN
}

\section{The Texas Tech community has made this publication openly available. Please share how this access benefits you. Your story matters to us.}

\begin{tabular}{|l|l|}
\hline Citation & $\begin{array}{l}\text { Henry, C., Vardeman, K., and Syma, C. (2012). Reaching out: } \\
\text { Connecting students to their personal librarian. Reference Services } \\
\text { Review 40(3), 396-407. } \\
\text { https://doi.org/10.1108/00907321211254661 }\end{array}$ \\
\hline Citable Link & $\underline{\text { http://hdl.handle.net/2346/68142 }}$ \\
\hline Terms of Use & $\underline{\text { CC-BY }}$ \\
\hline
\end{tabular}




\section{Introduction}

The field of librarianship is changing with the development of professional marketing, ever-changing technologies, and innovative outreach services. At Texas Tech University Libraries, librarians created new ways to communicate and connect with their patrons. Producing videos to make the library more approachable allows the user to see the library as a place of information, not intimidation. The videos give short, professional, informative messages that assist users. Deploying QR codes to assist users in a variety of ways throughout the library encourages the user to engage with the library. By developing a new outreach program called roving reference, librarians are meeting their patrons in their environment.

\section{Literature Review}

This literature review identifies how librarians have responded to the evolving model of reference services. The selected articles provide a background for the services developed at Texas Tech University Libraries. By delving deep into the 2009 Horizon Report, Neal (2009), addresses the hard questions facing academic libraries. He states that as users embrace diverse new technologies, research libraries must equip themselves to tackle technological questions. They must move with, not behind, their patrons in systems and technology, as patrons will expect assistance with all questions related to their research. While some of those questions will be information technology (IT) in nature, librarians should be able to answer those questions as part of their service to patrons. As changes in our profession continue, librarians will need to realize that "...we are taking on new roles, and these changing responsibilities are shifting the boundaries of the academic research library and reshaping user interaction" (p. 464). Neal comments on users: "They want us to be accessible and omnipresent-that is, always there everywhere they need us" (p. 468).

With reference transactions declining at most institutions, libraries are shifting resources, moving librarians off the traditional reference desk, or even removing the reference desk completely (Ford, 1986; Flanagan and Horowitz, 2000). Reference librarians are embracing new roles, increasing instruction and outreach initiatives for their communities, but also collaborating with more faculty and students on an individual level (Aguilar et al., 2011). Spak and Glover (2007) explained the long-standing personal librarian program at Yale's Cushing/Whitney Medical Library, in which librarians make personal contact with medical students to offer individual research assistance. Student response to the program has been highly favorable, with students desiring more communication with their personal librarians.

Covone and Lamm (2010) cover an in-depth plan that the Johnson \& Wales University Library put into place on their campus. This plan identified three levels that the Johnson \& Wales University Library decided to address: the campus, department, and the classroom. They outline initiatives such as satellite librarians, campus conferences, introductory classes taught by librarians, using departmental librarians, and librarians embedded in the face-to-face and online classroom. Covone and Lamm state "Our program planning is becoming more proactive than reactive as we strive to meet users where, when, and how they need us" (p. 207). Kilzer (2011) suggests that academic libraries must integrate into 
campus infrastructure, yet be agile enough to respond to the changing needs of their users, and discusses the transformation of reference interactions from traditional modes to specialized consultations, virtual mediums, and partnerships across the university.

Lee et al. (2010, p. 88) contend, "Future changes in the landscapes of higher education, particularly the projected growth in online learning, will challenge libraries to maintain their visibility by meeting users at their point of need, whether in online spaces or near the library's front entrance." Lee et al. state, "Reference services have changed over the years as users' expectations and patterns of library usage have shifted. All types of libraries are exploring new and innovative ways to enhance reference assistance to, and interaction with, library users" (p. 81). Stover (2008) asserts that academic reference librarians must market their services creatively to successfully compete for students' attention.

Strategically differentiating themselves in both services and promotion demonstrates their value to user groups. Effective marketing incorporates design and emotion that enhances the customer experience (Circle, 2009).

Libraries are also incorporating emerging technologies into the reference model. Peters (2011) identifies new ways of asking and receiving answers that do not involve a reference desk, particularly by offering services accessible via mobile devices. Ashford (2010) believes Quick Response (QR) codes will soon be in the mainstream. In libraries, they combine virtual and physical worlds to provide useful content at the point of need.

Little (2011) writes that many academic libraries are producing videos to promote and market their services, provide instruction, share digital collections, and establish an online brand. The editorial by Mitchell and Watstein (2007) explores how some libraries are using videos and social media tools to reach patrons. These authors focus primarily on Facebook and YouTube. This piece speaks to the use of videos for various purposes within the library such as marketing and instruction and explains how libraries may "double their coupons" by posting on YouTube (p. 524).

\section{Your Personal Librarian}

The Texas Tech University Libraries have a Communications \& Marketing Department which reports directly to the Dean of Libraries. Following the hire of a new marketing director in 2008, the team added the positions of assistant director, electronic media coordinator, 3D animator, and graphic designer. These staff were hired for their varied skillsets in fields relating to marketing and design. The director and assistant director coordinates with library departments to promote services and events through integrated communications solutions utilizing current marketing knowledge, theory, and skills to facilitate connections between the libraries and its patrons. The team also works closely the university's Office of Communications \& Marketing to maintain consistent branding and identity.

With the increased emphasis on marketing in the library, the Communications \& Marketing employees and the librarians had to adapt to one another. As the library started to incorporate marketing into its daily operations, discussions between the marketing director and the head of the reference department 
began. In 2008, their idea was to integrate the subject librarians into a marketing campaign. Subject librarians serve as liaisons to the various colleges and departments on campus. They provide reference, collection management, and library instruction services for specifically assigned subject areas. Much like the program at Yale (Spak and Glover, 2007), the subject librarians would be promoted to students as "your personal librarian," encouraging students to view the librarian as a person that was approachable with whom they can connect on campus. One way to assess the success of the campaign is to view the number of librarians meeting one-on-one with students for research assistance or consultation. In the 2008 academic year, librarians met with 340 students. In 2009, the number increased to 561, and in 2010 , to 756 . This represented an increase of more than $120 \%$ in only two years.

\section{TTUTube Videos}

The Texas Tech University Libraries' Communications \& Marketing team began filming videos to introduce the personal librarians in November 2010. Eight out of the fourteen personal librarians have volunteered to appear in these video segments. The videos discuss the librarians' hobbies as a way to make the librarians more personable, authentic, and "real" to students. In each video, the librarian has a chance to talk about one of his or her passions or hobbies outside of the library. Topics covered include soccer, stained glass, pet prairie dogs, tennis, shooting pool, making tamales, horses, and playing piano. The subject areas that each personal librarian is responsible for are covered at the end of each video and contact information is displayed in the final shot. In some cases, it was necessary for the Libraries' Communications \& Marketing team members and librarians to travel off-campus to shoot the videos. Videos were edited so that they only run for two minutes, giving a glimpse into the librarians' lives outside of work. The Communications \& Marketing electronic media coordinator completed all editing in-house. There was no written script for the videos, the coordinator simply asked a series of questions then edited the pieces together to flow in a natural pattern. Some of the shoots were done outside while others took place indoors. There were variables to be considered while shooting the videos such as weather and space availability.

This type of marketing appears to be relatively new, based on recent literature reviews. While there are many colleges and universities that use videos to describe library services and offer 'how to' tutorials, there is relatively no information available on this particular type of marketing-marketing the librarian as a person. The TTU Libraries' Communications \& Marketing team used this innovative way to let users know about the librarians on a personal level in an attempt to make them more approachable. Not only can the librarians assist with research, but they might be at a local soccer game or concert! Often, students are intimidated for various reasons and reluctant to ask questions at service desks. Those involved in making these videos hope that viewing these short video segments will help students be less intimidated about seeking out librarians. 


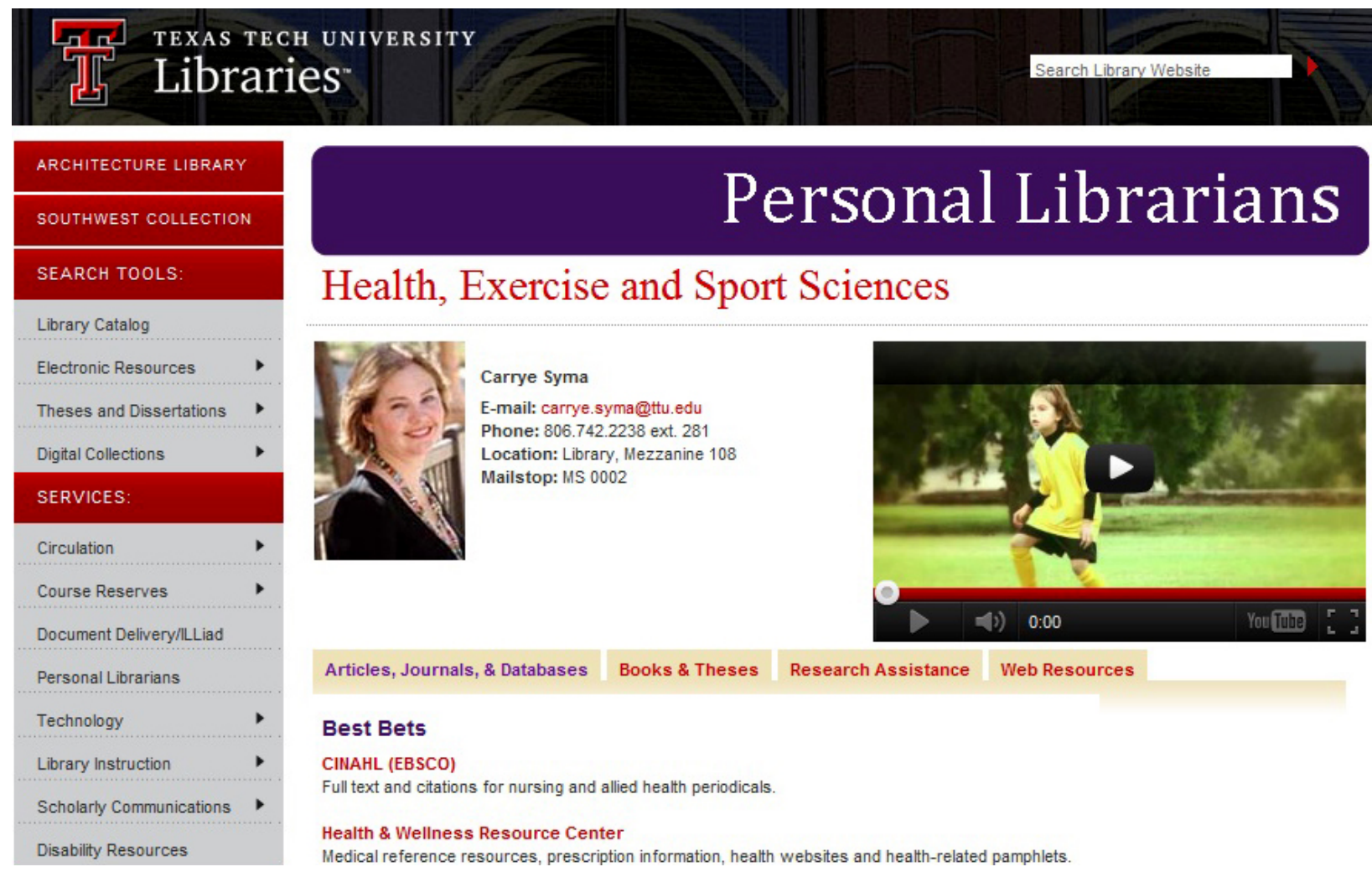

Figure 1. A personal librarian's website with video

As videos were completed over the next year, they were posted on the Libraries' YouTube channel, http://www.youtube.com/ttulib, which is accessible from the Libraries' homepage, http://library.ttu.edu/, as well as on the Libraries' Facebook page. YouTube is certainly one way to meet users where they are, rather than expecting them to come to the library. The librarians' videos are also embedded on the personal librarian pages so that anyone who accesses their page may view the video for that librarian, as seen in Figure 1. These videos have also been displayed throughout the library on mobile digital units (MDUs) and Wall-e. MDUs consist of a computer and a 40" flat-screen monitor on a wheeled platform. Five MDUs are located throughout the library on multiple floors, allowing the videos to be seen by more users. Wall-e is a large multi-screen digital wall stationed near the main entrance of the library. The videos are looped so that several play in succession on both devices.

The success of the Meet the Librarian video series should not be measured on views per video alone as viewing statistics cannot be gathered from the MDUs or Wall-e. Also, Facebook does not supply view counts for videos hosted on their site. However, the average number of views each video received on YouTube is 230 views per video. As of the spring of 2012, the total number of views for all videos on the Libraries' YouTube channel is 2,207. The success of the videos may be measured more accurately through the anecdotal evidence of patrons striking up a conversation in regard to the videos. The librarian staffing the service desk reported students commented about her piano playing when they met her at the desk. The personal librarian whose YouTube video has received the most views has also been approached by the most students who mentioned the video. 


\section{QR Codes around the Library}

In a large academic library building open around the clock, there are multiple floors without public services staff available to assist students. Recent literature contains many examples of academic libraries deploying Quick Response (QR) codes in their buildings (Walsh, 2010; Hicks and Sinkinson, 2011; Pulliam and Landry, 2011) in an effort to make services and resources available anytime and anywhere to the growing community of mobile device users. QR codes are two-dimensional barcodes, which can be read on mobile devices equipped with a camera and the proper software, usually a free application download. The barcodes contain information or links to e-resources. Posting QR codes in areas of the library that may be confusing allows users to connect to e-resources or request assistance without returning to a service point. This use of QR codes lets patrons with capable devices engage with the library in a more convenient way.

In 2010, the Texas Tech University Libraries began producing and installing signage utilizing QR codes around the library. The TTU Libraries' Communications \& Marketing team coordinated QR code generation for new signage around the library utilizing QR codes. Having a central person or team direct the initiative created a uniform look on the signs around the library and avoided duplicative work where staff would repeatedly create codes pointing to the same destination. This also established a central repository for gathering statistics.

Before QR codes were printed and posted around the library, they were tested on a variety of mobile devices and reader applications (apps). Library staff tested the codes on iPhone, RIM (Blackberry), Android, and Palm smartphones with the QR reader apps BeeTagg and i-Nigma. The user experience usually varied among the operating systems. For example, with a QR code resolving to a librarian's contact information (vcard), some users could save the contact details to their phone's "contacts/address book" and also call the number directly from the contact information displayed. Others only saw a scrolling message with the text of the librarian's contact information. A code directing users to the library chat service did not work with some mobile browsers. The Communications \& Marketing team also found that certain QR code generators produced codes that performed better on more devices.

In the five stacks levels where there are no service desks, small signs posted at the ends of the aisles use QR codes to direct users to the Texas Tech University Libraries' customized WorldCat site or to the library chat service. Brief instructions explain how to download a QR Code reader app. Shortened URLS appear next to the codes for users who prefer to type the URL into a browser. On the library's ground floor, four freestanding scanners are available for any patron to walk up and use for free. Most people find the scanners to be easier and faster to use than a copier, but some patrons are not sure how to begin using them. Signs on the scanners have $Q R$ codes directing users to an instructional video on the Libraries' YouTube channel. Table tent signs placed in public computing areas advertise mobile library services to students with a code pointing to the Libraries' mobile website.

Next to the personal librarians' office doors is a nameplate with the librarian's name, title, contact 
information, and subject specialization. Three QR codes appear prominently that direct users to "Ask a Question via Chat," "Email Me," and "Add to Contacts." The first code links to the library chat service, the second sends an email to the librarian, and the third code connects to the librarian's contact information (vcard).

Some of the personal librarians have opted to hold office hours in other buildings in an effort to reach out to students in their subject areas. The Communications \& Marketing team designed a personalized table tent with the introduction "Hi! Meet Your Personal Librarian," followed by the librarian's name, a list of her subject specialties, and her contact information. QR codes on the sign resolve to the chat service or send an email to the librarian. This signage serves a dual purpose of advertising the service that the librarians are providing and offering a way for students to contact a librarian at any time.

In 2009, circulation and reference at Texas Tech University Libraries merged into one "service desk" near the main entrance. A detailed discussion of the service point consolidation is tangential, but literature abounds on the topic, such as Flanagan and Horowitz (2000), and Sonntag and Palsson (2007), who identify merging as a successful response to decreasing reference transactions. Typically, the questions asked at the service desk are a mix of directional and reference questions. The service desk is always staffed with one or more student assistants and usually with a circulation staff member. Additionally, a personal librarian for reference staffs the service desk and virtual reference services for several hours a day, Monday-Friday, but there are many hours that the library is open that a librarian is not at the service desk. Because of this, there was a need to create signage that directed patrons to reference services during those off-hours and also made a distinction between the reference librarian and the other staff at the service desk. The reference librarian met with the director of the Libraries' Communications \& Marketing team to discuss a sign using QR Codes for the service desk. They made plans for a two-sided sign: the side showing when the librarian was at the desk would direct patrons to another station for checkout, and the other side would have codes connecting patrons to the librarian's contact information. The side using QR codes had a photo of the librarian above three QR codes. The first code connects to the librarian's contact information (vcard), the second links to the library chat service, and the third sends an email to the librarian.

To date, efforts to educate users on how to use the QR codes were generally targeted and informal. For example, during library building tours, librarians showed students the QR codes at the end of the stacks aisles and demonstrated how to use them. At orientation sessions for new or prospective students, librarians managed an information table about library services. They handed out flyers with a QR code resolving to the library mobile website and talked to students about how to download a QR code reader app and use QR codes. At a library services fair, staff at the social media booth talked to students about the QR codes around the library and helped students scan them.

The web-based BeeTagg software provided statistics on QR code usage for the libraries. To date, usage has been very low, with most codes not scanned more than a handful of times. Additionally, the BeeTagg software, which was available at no cost when the project originated, abruptly began charging fees to access usage statistics, making ongoing assessment problematic. 
The observation of unexpectedly low use of QR codes brings into question whether the library should continue to install signage utilizing them. Although many libraries were early adopters of this new technology, users on this campus have not readily embraced it. Some of the signs with QR codes are still functional, such as the nameplates and table tents listing correct contact information in addition to the QR codes. However, the widely distributed signs in the stacks aisles were removed to update an outdated link. At that time, librarians took the opportunity to suggest that QR codes be replaced with directions to the text message reference service, which is a more accepted and user-friendly mode of assistance. Until there is a shift in user behavior, QR codes should not be re-deployed.

\section{Leaving the Library with Roving Reference}

Texas Tech University librarians saw a need to make the library more approachable and to meet the needs of students wherever they were... literally. To address this need, three personal librarians started a roving reference service where they wheeled a cart outside to canvas the campus, answering all types of questions. The project's first objective was to change how service was initiated to create a way for librarians to approach students, instead of students initiating the first contact. The next objective was to respond to increased enrollment by interacting with new students and visitors. Finally, librarians hoped that once a student experienced a positive interaction, $s$ /he would be more likely to approach a librarian in the future.

In 2008, librarians tested the WiFi signal on campus and found it was not sufficient to maintain a connection outside any of the academic buildings. In 2010, the strength had improved enough to allow them to travel with an Internet-connected laptop. Balancing a laptop while assisting students was impractical. Buying a media cart with wheels allowed the librarians to mobilize their service to students across the TTU campus. To create an identity for the roving reference cart, librarians presented ideations to the Communications \& Marketing graphic designer, who produced an outstanding design that would be installed on the cart. In the design, a red tone-on-tone asterisk is behind the white text, drawing the eye to the center of the sign, as seen in Figure 2. To complement the cart, librarians purchased bright red t-shirts and added "L?ST" to match the design.

Librarians hit the ground roving during the summer of 2010, with a big push at the beginning of the fall semester. The librarians traveled around campus in teams of one or two assisting students, parents, and even a new faculty member. Librarians fielded all kinds of questions from "Where is Holden Hall?" to "I saw a documentary last night on wind energy. Can you help me find more on this topic?" Using laptops, iPads, smartphones, and the campus wireless Internet, they connected students to the information needed. Librarians supplied maps, directions to buildings, provided access to look up course schedules, and if needed, demonstrated TTU Libraries' resources. Roving reference librarians also explained the personal librarian program in which each field of study has a dedicated librarian to help with assignments and research. While roving librarians planned to rove throughout the semester to answer reference questions, students needed directional assistance and stopped approaching the cart after the 
first week of the semester. They also discovered that specific buildings had higher concentration of freshman, which caused heavier traffic for roving reference.

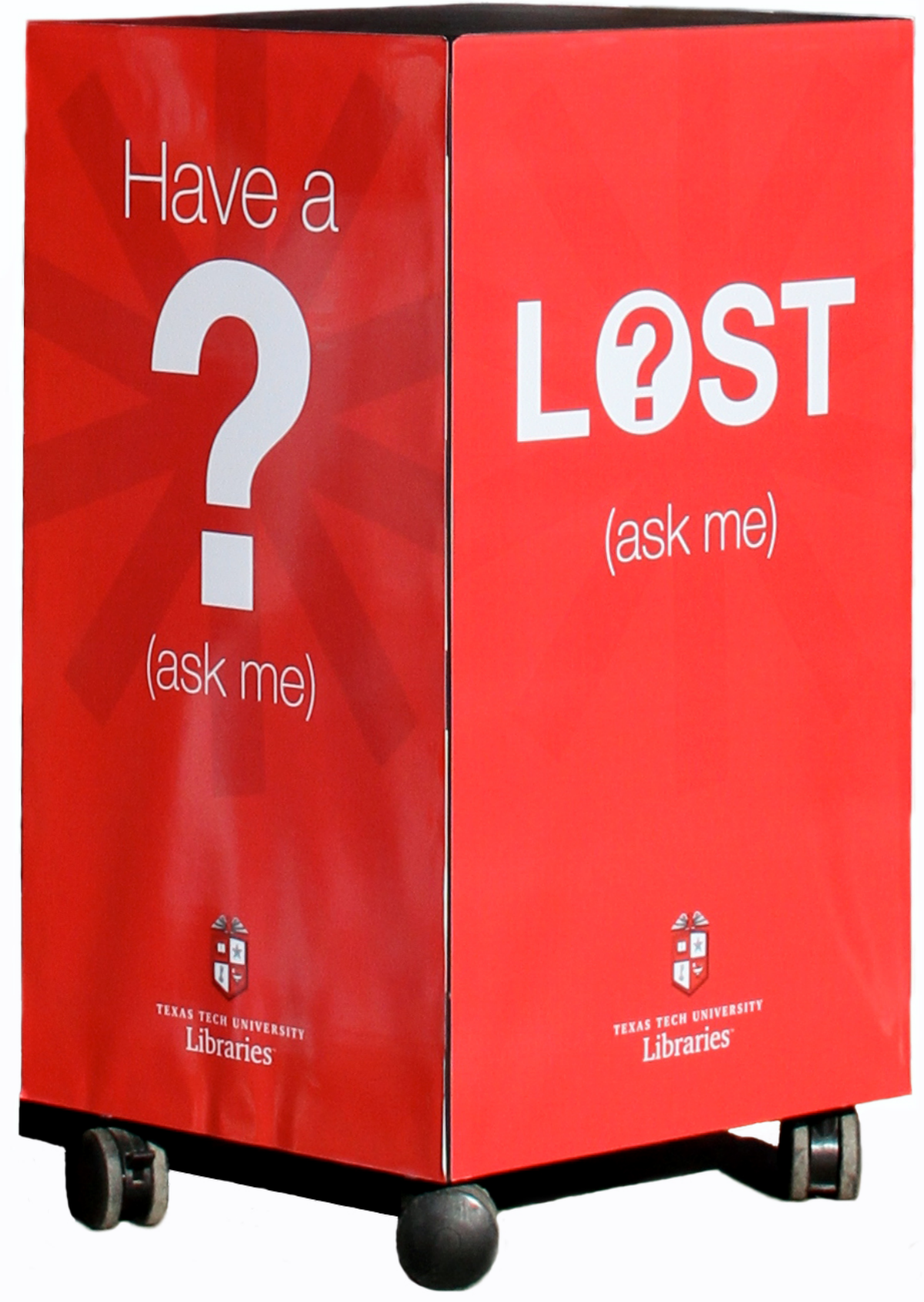

Figure 2. The roving reference cart

To promote roving reference, librarians engaged in new activities to encourage use of the service. One of the roving reference librarians took the cart to Raiderville, a tent community around the football stadium where 2,000 students camped out before a rival football game, and gave out contact information for the students' personal librarians and swag from the libraries. Additionally, attending Red 
Raider Orientation sessions proved useful. During the summer of 2011, over 4,500 freshmen and transfer students attended one of the eighteen orientation sessions offered. Upperclassmen serve as counselors to assist new students through the orientation process. Roving reference librarians were excited to hear counselors tell the new students to look for the cart if they needed help during the first week of school. The current class of students appreciated the service enough to recommend it to the incoming class.

Students responded positively to the roving reference service. Even with teams of two, during the first two weeks of the fall semester the cart was so overwhelmed that the librarians could not tally all the questions due to the mass of people in the queue. Librarians talked to countless students and answered at least ninety-three patrons' questions. The librarians created a three-question survey to collect feedback from patrons:

- Would you use this service again?

- Do you think you are more likely to use the Libraries after using the Roving Reference service?

- How could this service (Roving Reference) be improved?

Twenty-three students responded to the survey. All answered the first two questions affirmatively. Only one survey included a suggestion for improvement, which was to add a printer to the cart. Some representative comments gathered from the surveys are:

- I learned something new already.

- Need more of them [roving reference carts]

- What a great idea!

- I bet you are a life saver to a lot of students. That's a wonderful idea!

Even though the survey was short, it slowed the students and the librarians down. After the fall semester of 2010, the roving reference librarians opted for a simpler method of collecting statistics. The librarians used tick marks to track which days of the week and times of the day roving reference was most utilized. With this adjustment in place in the fall of 2011, librarians assisted 342 students across seven days, a $366 \%$ increase from the year before. Over $80 \%$ of the questions occurred on the first two days of the semester. Armed with more than just campus maps, the librarians gathered bus schedules and the personal librarian directory to hand out to students when certain questions arose. At the beginning of the spring semester of 2012, librarians braved the winter and assisted ninety-eight students. The librarians were excited to see the service grow and hope to see another sizable increase in the fall of 2012.

By assessing the execution of this service, the librarians gained knowledge which allowed them to continuously adapt the project. While this service was developed to answer reference questions, librarians answered more directional questions. However, roving reference clearly met a need on campus. The project did not require the time commitment anticipated, because demand peaked on the first two days of the semester. Although the start of the semester is a busy time in the library, students are not yet working on research that requires librarians' assistance. Most questions can be handled by 
paraprofessionals, allowing librarians to devote time to this project. Because certain areas of campus had heavier traffic and higher freshman populations, librarians chose to focus on those areas exclusively. Roving librarians concluded that the project should be a permanent service that operates at the beginning of the semester to continue making personal connections.

\section{Conclusion}

Texas Tech University librarians are reaching users by making the most of the technologies available, and in many cases, thinking "outside the box" to meet challenges presented along the way. The libraries developed ways to market the personal librarians that will continue to engage patrons for years to come. The Meet the Librarian video series proactively introduced students to their librarians. Displaying QR codes to provide assistance in areas of the library without service points proved to be an ineffective outreach strategy. The roving reference outreach program had a successful response and created an entirely new service point. By embracing professional marketing, ever-changing technology, and innovative outreach services, librarians will need to be creative as they strive to connect to their users on a more personal level. 


\section{References}

Aguilar, P., Keating, K., Schadl, S., and Van Reenen, J. (2011). "Reference as outreach: meeting users where they are", Journal of Library Administration, Vol. 51 No. 4, pp. 343-358.

Ashford, R. (2010), "QR codes and academic libraries: reaching mobile users", College and Research Libraries News, Vol. 71 No. 10, pp. 526-531.

Circle, A. (2009), "Marketing trends to watch", Library Journal, Vol. 134 No. 16, pp. 26-29.

Covone, N. and Lamm, M. (2010), "Just be there: campus, department, classroom...and kitchen?", Public Services Quarterly, Vol. 6 No. 2/3, pp. 198-207.

Flanagan, P. and Horowitz, L. (2000), "Exploring new service models: can consolidating public service points improve response to customer needs?", The Journal of Academic Librarianship, Vol. 26 No. 5, pp. 328-329.

Ford, B.J. (1986), "Reference beyond (and without) the reference desk", College and Research Libraries, Vol. 47 No. 5, pp. 491-94.

Hicks, A. and Sinkinson, C. (2011), "Situated questions and answers: responding to library users with QR codes", Reference \& User Services Quarterly, Vol. 51 No. 1, pp. 60-69.

Kilzer, R. (2011). "Reference as service, reference as place: a view of reference in the academic library", The Reference Librarian, Vol. 52 No. 4, pp. 291-299.

Lee, M., Ritterbush, J., and Sivigny, R. (2010), "Reference at the commons: a case study", Reference Services Review, Vol. 38 No. 1, pp. 81-89.

Little, G. (2011), "The revolution will be streamed online: academic libraries and video", Journal of Academic Librarianship, Vol. 37 No. 1, pp. 70-72.

Mitchell, E. and Watstein, S.B. (2007), "The places where students and scholars work, collaborate, share and plan", Reference Services Review, Vol. 35 No. 4, pp.521-524.

Neal, J.G. (2009), "What do users want? What do users need? W(h)ither the academic research library?", Journal of Library Administration, Vol. 49 No. 5, pp. 463-468.

Peters, T.A. (2011), "Left to their own devices: the future of reference services on personal, portable information, communication, and entertainment devices", The Reference Librarian, Vol. 52 No. 1, pp. 88-97.

Pulliam, B. and Landry, C. (2011), "Tag, you're it! Using QR codes to promote library services", Reference Librarian, Vol. 52 No. 1/2, pp. 68-74.

Sonntag, G., and Palsson, F. (2007), "No longer the sacred cow-no longer a desk: transforming reference service to meet $21^{\text {st }}$ century user needs", Library Philosophy and Practice, Vol. 9 No. 2 , available at: http://www.webpages.uidaho.edu/ mbolin/sonntag-palsson.htm (accessed 12 May 2012).

Spak, J.M., and Glover, J.G. (2007), "The personal librarian program: an evaluation of a Cushing/Whitney Medical Library outreach initiative", Medical Reference Services Quarterly, Vol. 26 No. 4, pp. 1525.

Stover, J. (2003), "Be you; be unique: how to create competitive reference services by being strategically different", Steiner, S.K. and Madden, M.L. (Eds.), The Desk and Beyond: Next Generation Reference Services, Association of College and Research Libraries, Chicago, pp. 135-147. 
Walsh, A. (2010), "QR codes: using mobile phones to deliver library instruction and help at the point of need", Jounral of Information Literacy, Vol. 4 No. 1, pp. 55-63. 


\section{About the Authors}

Cynthia L. Henry, an Associate Librarian, has been a librarian since graduating from Texas Woman's University in 2004. Hired as a subject librarian at Texas Tech University in 2005, she enjoys working on an academic campus. Meeting faculty and student research needs from her subject area the College of Human Sciences is a rewarding experience in addition to being an instructor for the Introduction to Library Research. Cynthia L. Henry is the corresponding author and can be contacted at: cynthia.henry@ttu.edu.

Kimberly K. Vardeman, a General Reference Librarian at the Texas Tech University Library, received her MS in Library Science from the University of North Texas in 2008. She is one of the instructors for the Introduction to Library Research course and is generally found at the service desk helping patrons. She is a member of the American Library Association and Texas Library Association and has presented at the Texas Library Association Annual Conference. Outside of the library, she is a skilled classical pianist who teaches piano lessons privately.

Carrye K. Syma graduated from the University of North Texas in 2003 while working as a librarian at South Plains College. In 2005 she joined the ranks of Texas Tech University. Responsible for the departments of Communication Studies and Health, Exercise and Sport Sciences and the College of Mass Communications she enjoys interacting with users. 